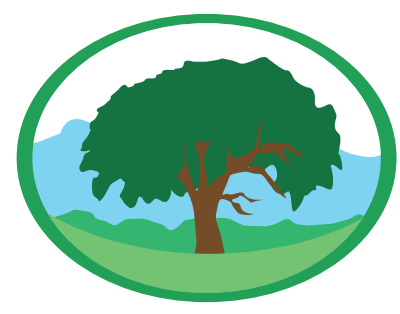

\title{
VIABILIDADE DE MÉTODOS PARA SUPERACÃO DE DORMÊNCIA E ANÁLISE MORFOMÉTRICA DAS SEMENTES DE PUERÁRIA
}

PINHEIRO, R. M. ${ }^{1}$; MACEDO, V. G. K. ${ }^{1}$; SOARES, V. N. ${ }^{1}$; TUNES, L. V. M. ${ }^{1}$; ALMEIDA, A. S. ${ }^{1}$;

1 Universidade Federal de Pelotas

Palavras-chave: escarificação; Fabaceae; germinação.

\section{Resumo}

A puerária (Pueraria phaseoloides (ROXB.) BENTH) é uma espécie forrageira, que apresenta sementes com dormência tegumentar, sendo bem característicos nas Fabaceae. Com este trabalho, objetivou-se avaliar diferentes métodos de superação de dormência, morfometria e massa fresca de sementes de puerária. 0 trabalho foi dividido em dois estudos, sendo o primeiro (I) relacionado aos métodos de superação de dormência lescarificação com lixa e punção, imersão em água por 24 e 8 horas, imersão em água a $80^{\circ} \mathrm{C}$ por 5 minutos, e o controle) e o segundo (II) destinado para determinar a morfometria e massa fresca das sementes. Para ambos os estudos, foi utilizado delineamento inteiramente casualizado. Para avaliar o efeito dos tratamentos, as sementes do estudo I foram avaliadas pela germinação e índice de velocidade de germinação e no estudo II foi avaliado o comprimento, largura, espessura e massa fresca das sementes. Os métodos que se mostraram com melhor potencial de superação de dormência foram a escarificação mecânica por meio de punção e lixa. Quanto à avaliação morfométrica das sementes $P$. phaseoloides, dentre as variáveis analisadas como características físicas a massa fresca foi a que apresentou maior coeficiente de variação e entre as dimensões foi largura $10,48 \%$.

\section{VIABILITY OF METHODS FOR DORMANCY OVERCOMING AND MORPHOMETRIC ANALYSIS OF PUERÁRIA SEEDS}

Keywords: scarification;

Fabaceae; forage; germination.

\section{Abstract}

The puerária (Pueraria phaseoloides (ROXB.) BENTH) is a forage species, which presents seeds with integument dormancy, being very characteristic in Fabaceae. The objective of this study was to evaluate different methods of overcoming dormancy, morphometry and fresh mass of puerária seeds. The study was divided in two studies, the first one being related to the methods of dormancy overcoming (scarification with sandpaper and puncture, immersion in water for 24 and 8 hours, immersion in water at $80^{\circ} \mathrm{C}$ for 5 minutes, and control) and the second one (II) to determine morphometry and fresh seed mass. For both studies, a completely randomized design was used. To evaluate the effect of the treatments, the seeds of study I were evaluated by the germination and speed index of germination and in study II the length, width, thickness and fresh mass of the seeds were evaluated. The methods that showed the best potential for overcoming numbness were mechanical scarification through puncture and sandpaper. As for the morphometric evaluation of the P. phaseoloides seeds, among the variables analyzed as physical characteristics, the fresh mass was the one with the highest coefficient of variation and $10.48 \%$ of the dimension. 


\section{INTRODUÇÃO}

A Amazônia brasileira concentra grande área improdutiva devido à degradação dos solos. Tendo como principais causas diretas a pecuária, a agricultura de larga escala e a agricultura de corte e queima (Rivero, 2009). A vegetação predominante na Amazônia é a Floresta Ombrófila Densa, que corresponde a 41,67\% do bioma. Destes, cerca de $12,47 \%$ foram alterados pela ação do homem, sendo que $2,97 \%$ encontramse em recuperação (vegetação secundária) e 9,50\% destina-se para o uso agrícola ou pecuária (MMA, 2014).

A utilização destas áreas para pecuária acarreta na degradação das pastagens, contribuindo para perda de áreas produtivas. Na Amazônia, estima-se que cerca de 30 milhóes de hectares, ou em torno de 50\% das pastagens plantadas estejam degradas ou em processo de degradação (Dias-Filho, 2011). E após cada ano tende a aumentar, Dias-Filho (2014) estimou cerca de 100 milhóes de hectares para os próximos 4 anos que poderá entrar em processo de degradação. Neste contexto, existe a necessidade de tomar medidas estratégicas para restruturação dos solos degradados, na qual pode-se fazer uso de espécies nativas dos biomas brasileiros com potencial de reestruturação dos solos já em processo avançado de compactação (Marques et al., 2014). Porém, pode ser citado uma espécie (puerária) de alta adaptabilidade na Amazônia com fins para pastagens e cobertura verde.

A puerária como é conhecida vulgarmente pertence à família Fabaceae, uma espécie utilizada na cobertura verde do solo e de acordo com Pinheiro et al. (2017), ela é importante para uso na nutrição animal e recuperação de áreas degradas. Apresenta teores de proteína bruta variando entre 16 e $19 \%$. Sendo utilizada na forma de feno, farinha, silagem, além do pastejo direto, pura ou consorciada com gramíneas (Costa, 1990; Monteiro et al., 2009, Costa et al., 2012). Em algumas sub-regióes da Amazônia, a maioria dos pequenos produtores realizam a semeadura a lanço ou consorciada com a cultura do milho ou arroz, após este processo mantémse a cobertura no solo (Pinheiro et al., 2017).

No entanto, Sousa Filho et al. $(\mathrm{s} / \mathrm{d})$, considera que existe problema degerminação (dormência tegumentar) nesta espécie. Devido a isso, estudos relacionados à superação de dormência são de relevante importância para propagação desta forrageira. Visando atende estes pressupostos, objetivou-se avaliar diferentes métodos de superação de dormência, morfometria e massa fresca de sementes de puerária

\section{MATERIAL E MÉTODOS}

O trabalho foi conduzido no Laboratório de Análise de Sementes da Faculdade de Agronomia Eliseu Maciel, pertencente à Universidade Federal de Pelotas, situada no município de Capão do Leão, RS. Foi utilizado sementes de puerária em estágio de maturação fisiológica provenientes do município de Brasiléia, no estado do Acre, coletadas em julho de 2016 e armazenadas em garrafa "pet”, com teor de água em torno de $10 \%$. Sendo determinado pelo método de estufa a temperatura de $105^{\circ} \mathrm{C}$, conforme a regras para análise de sementes (Brasil, 2009).

A pesquisa foi dividida em dois estudos:

Estudo I

Os tratamentos consistiram da combinação de cinco métodos de superação de dormência mais o controle (sementes intactas): escarificação com punçáo, imersão em água ambiente por 8 e 24 horas, e imersão em água em temperatura de $80^{\circ} \mathrm{C}$ por 5 minutos, escarificação com lixa de granulometria 80 e o controle (sementes sem receber nenhum tratamento).

A germinação foi conduzida com cinco repetiçóes de 50 sementes, estas foram colocadas em caixas plásticas do tipo gerbox com duas folhas de papel germitest, umedecidas com água destilada na proporção de 2,5 vezes o peso do papel seco, logo após os gerbox foram conduzidos e mantidos em germinador à temperatura de $25^{\circ} \mathrm{C}$. As avaliaçóes (plantas normais, anormais, sementes duras, mortas e percentual de germinação) foram efetuadas conforme as Regras para Análise de Sementes aos quatro dias após a semeadura (Brasil, 2009). Exceto, a germinação que foi contabilizado após dois dias da semeadura.

Os efeitos das escarificações sobre o desempenho das sementes foram avaliados pelo teste de germinação, sendo contadas diariamente as que apresentavam emissão da raiz primária maior que $2 \mathrm{~mm}$ de comprimento, e o período de duração do teste foi 
determinado como sendo o número de dias a partir do qual houve estabilização da germinação; também foi calculado o índice de velocidade de germinação (IVG) de acordo com a fórmula proposta por Maguire (1962).

$\mathrm{O}$ experimento foi instalado em delineamento inteiramente casualizado, com quatro repetiçôes. Posteriormente, os dados foram submetidos a análise de variância, e quando significativos, as médias foram comparadas pelo teste de Tukey a $5 \%$ de probabilidade. Analisado no programa estatístico WinStat.

\section{Estudo II}

Para a caracterização morfométrica das sementes de puerária foi selecionado ao acaso 200 sementes, e posteriormente avaliadas quanto ao comprimento $(\mathrm{mm})$, largura $(\mathrm{mm})$, espessura $(\mathrm{mm})$, peso de massa fresca. As avaliaçóes foram feitas com paquímetro digital $(0,01 \mathrm{~mm})$ e em balança digital $(0,001 \mathrm{~g})$, respectivamente.

Para todas as variáveis avaliadas foram calculados os valores máximo e mínimo, média, desvio padrão (DP), coeficiente de variação $(\mathrm{CV})$ e correlação de Pearson (r). Este coeficiente varia de $-1 \mathrm{a}+1$ e quanto mais próximo desses valores, mais forte é a correlação entre as variáveis examinadas (AYRES et al., 2007). A estatística descritiva e o coeficiente de correlação de Pearson foram calculados com o auxílio do programa estatístico BioEstat 5.0.

\section{RESULTADOS E DISCUSSÃO}

Inicialmente, as sementes de $P$. phaseoloide apresentavam o teor de água em torno de $10 \%$. As contagens do número de sementes germinadas iniciaram-se aos dois dias, utilizando-se como critério de plântula normal a expansão do eofilo com todas as estruturas essenciais da plântula em perfeito estádio de desenvolvimento.

Os resultados da percentagem de germinação, de sementes duras e mortas, de plântulas normais e anormais e o do índice de velocidade de germinação de sementes de puerária são apresentados na Tabela 1. Dentre as variáveis de análise fisiológicas, o índice de velocidade de germinação permitiu evidenciar diferenças entre os tratamentos. Já em relação a germinação das sementes, a mesma teve início observado no segundo dia após a semeadura, isso para todos os tratamentos, exceto para a testemunha.

$\mathrm{O}$ tratamento de imersão em água à temperatura ambiente por 8,24 horas e a temperatura de $80{ }^{\circ} \mathrm{C}$ durante 5 minutos $\left(80^{\circ} \mathrm{C} / 5^{\prime}\right)$, se mostram menos eficiente, tendo apresentado, juntamente com a testemunha, as menores percentagens de germinação, os mais baixos índices de velocidade de germinação, além de ter apresentando as maiores percentagens de sementes duras e mortas.

Esses resultados comprovam a necessidade de tratamentos de superação de dormência para puerária, que seja, algum tipo de rompimento do tegumento das sementes. De acordo com Gama et al. (2011), a impermeabilidade do tegumento pode ser superada por tratamento de abrasividade. Pois houve maior formação de plântulas normais nos tratamentos com escarificação mecânica punção e lixa, para imersão em água ambiente por 8, 24 horas e a temperatura de 80 ${ }^{\circ} \mathrm{C}$ foram superiores somente da testemunha.

Tabela 1. Valores médio quanto às contagens de germinação, sendo plântulas normais (PN), plântulas normais (PA), sementes duras (SD) e sementes mortas (SM), germinação (G\%) e índice de velocidade de germinação (IVG) de após procedimentos de escarificação.

\begin{tabular}{lllllll}
\hline TRATAMENTOS & PN & PA & SD & SM & G\% & IVG \\
\hline Escarificaçáo Punçáo & $38 \mathrm{~b}$ & $5 \mathrm{a}$ & 4 & 3 & $86 \mathrm{a}$ & $3,66 \mathrm{a}$ \\
Imersão em $\mathrm{H}_{2} \mathrm{O} 24 \mathrm{~h}$ & $18 \mathrm{~d}$ & $3 \mathrm{~b}$ & 19 & 10 & $42 \mathrm{c}$ & $1,44 \mathrm{~b}$ \\
Imersão em $\mathrm{H}_{2} \mathrm{O} 8 \mathrm{~h}$ & $16 \mathrm{de}$ & $2 \mathrm{c}$ & 19 & 13 & $36 \mathrm{~cd}$ & $1,59 \mathrm{~b}$ \\
Imersão em $\mathrm{H}_{2} \mathrm{O} 80^{\circ} \mathrm{C} / 5^{\prime}$ & $28 \mathrm{c}$ & $4 \mathrm{~b}$ & 10 & 8 & $64 \mathrm{~b}$ & $1,83 \mathrm{~b}$ \\
Escarificação Lixa & $44 \mathrm{a}$ & $4 \mathrm{~b}$ & 0 & 2 & $96 \mathrm{a}$ & $3,75 \mathrm{a}$ \\
Controle & $13 \mathrm{e}$ & $3 \mathrm{~b}$ & 34 & 0 & $32 \mathrm{~d}$ & $0,53 \mathrm{c}$ \\
\hline
\end{tabular}

Médias seguidas pela mesma letra, estatisticamente não diferem pelo teste de Tukey a nível $5 \%$ de probabilidade.

Medeiros Filho et al. (2002), relataram que a escarificação mecânica provoca fissuras no tegumento, aumentando a permeabilidade e permitindo a embebiçáo e, consequentemente, o início da germinação. Por isso são um método mais importante para superação de dormência das espécies que apresentam essas características. Melo et al. (2011), estudando superação de dormência em sementes de espécies de Parkia ssp, relatam que os melhorem resultados sobre germinação 
e tempo médio de germinação foi quando realizou punção com agulha quente e escarificação com esmeril elétrico. Desta forma, para espécie que apresentam tegumento muito duro, estes são os métodos mais eficientes para superaçáo de dormência.

De forma geral, houve uma tendência de os maiores valores de porcentagem de germinação estarem associados às maiores médias de velocidades de germinação. Este mesmo comportamento foi observado por Andrade et al. (1997) e Sampaio et al. (2001), para sementes de sucupira preta, indicando a existência de uma relação direta entre os dois processos.

Quanto à análise morfométrica das sementes (Tabela 2), os valores observados variaram entre 0,0018 e 0,0171 (média de 0,012 g) para a massa, 1,41 e 2,78 mm (média de 2,32 $\mathrm{mm}$ ) para o comprimento;2,60 e 3,86 $\mathrm{mm}$ (média de $3,03 \mathrm{~mm}$ ) para a largura e para a espessura variando de 1,14 e 3,86 (média de 2,042 $\mathrm{mm}$ ). Vale destacar, com exceção da massa seca, as variáveis biométricas apresentaram baixo coeficiente de variação.

Tabela 2. Estatística descritiva da morfometrica de sementes de $P$. phaseoloides. $\mathrm{DP}=$ desvio padrão, $\mathrm{CV}=$ coeficiente de variação.

\begin{tabular}{llllll}
\hline $\begin{array}{l}\text { Características } \\
\text { biométricas }\end{array}$ & Mínimo & Máximo & Média & DP & CV (\%) \\
\hline Semente & & & & & \\
\hline Massa Fresca (g) & 0,0018 & 0,0171 & 0,012 & 0,0023 & 19,51 \\
Comprimento (mm) & 1,41 & 2,78 & 2,32 & 0,191 & 8,24 \\
Largura (mm) & 2,60 & 3,86 & 3,03 & 0,318 & 10,48 \\
Espessura (mm) & 1,14 & 2,47 & 2,042 & 0,194 & 9,49 \\
\hline
\end{tabular}
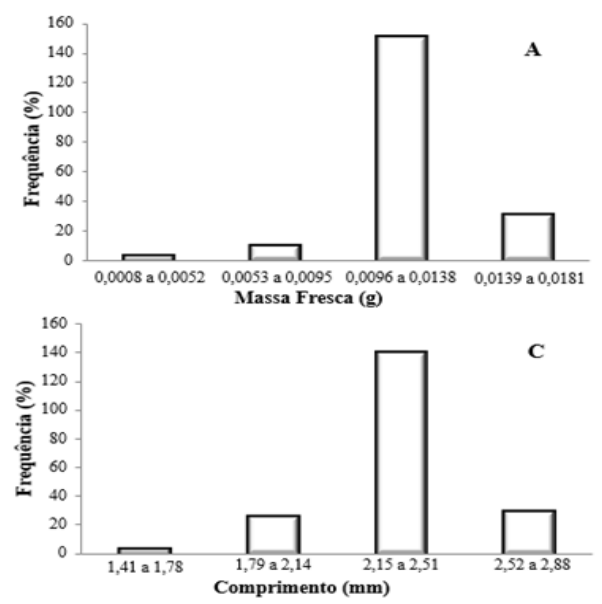

Das variáveis avaliadas, a massa fresca da semente foi a que apresentou maior coeficiente de variação $(\mathrm{CV}=19,51 \%)$. De acordo com Macedo et al. (2009), a influência do ambiente sobre o desenvolvimento da semente é traduzida principalmente por variaçôes no tamanho, peso, potencial fisiológico e sanidade. Podese observar na tabela 1 que o valor do desvio padrão e do CV desses parâmetros é relativamente baixo, indicando baixa heterogeneidade da amostra. Isto pode ser um indicativo de que as sementes tiveram pouca influência dos fatores ambientais, que se traduz no desenvolvimento das mesmas. Para Oliveira et al. (2012), o possível efeito dos fatores ambientais é traduzido principalmente no potencial fisiológico e na sanidade das sementes.

O conhecimento da variação morfométrica de sementes é importante para selecionar as características (dimensóes), seja no sentido de aumento ou uniformidade de emergência. Assim, a distinção e classificação das sementes quanto à massa e tamanho é uma maneira eficiente de melhorar a qualidade de lotes de sementes em relação à uniformidade de emergência e vigor das plântulas (Pedron et al., 2004).

$\mathrm{Na}$ Figura 1 é possível observar que a maioria das sementes que foram avaliadas integram intervalos de classes de massa medianos, entre 0,0096 a 0,0181 g (76\%). O mesmo se observa em relação ao comprimento, onde intervalos de classe medianos $(2,15$ a $2,88 \mathrm{~mm})$ predominaram em $86 \%$ dos casos. $\mathrm{Na}$ variável espessura foi predominante as sementes $(82 \%)$ que integram intervalos de classe menores, entre 1,87 e $2,57 \mathrm{~mm}$. Para a largura foi de predominância entre 2,54 a $3,48 \mathrm{~mm}(90 \%)$.

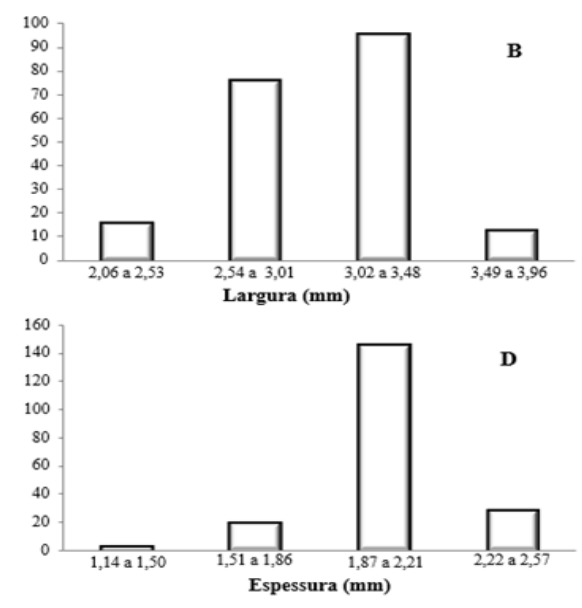

Figura 1. Frequência da Massa (A), largura (B), comprimento (C) e espessura (D) de P. phaseoloides. 
De maneira geral, todas as variáveis avaliadas apresentaram baixos coeficientes de variação $(\mathrm{CV})$. Possivelmente, isso ocorra devido as plantas estarem muito próximas entre si, o que pode favorecer a endogamia (Maués; Oliveira, 2010). Outra possibilidade é que a baixa variabilidade decorre de uma condição natural da espécie, que se expressa nas características morfológicas, tanto de frutos, bem como das sementes.

A análise de correção de Pearson ( $r$ ) mostrou que todos os valores obtidos foram positivos (Tabela $3)$, indicando que as variáveis dependem em menor ou maior grau, umas das outras. É possível observar correlaçáo moderada e positiva entre a massa e a espessura da semente $(0,7134)$, o que é esperado tendo em vista que elas são proporcionalmente dependentes, pois quanto maior for espessura mais pesado será a sementes.

Tabela 3. Correlação de Pearson (r) para as variáveis biométricas das P. phaseoloides. MS - Massa da semente; CS - Comprimento da semente; LS - Largura da semente; ES - Espessura da semente.

\begin{tabular}{lllll}
\hline & MF & LS & CS & ES \\
\hline MF & - & - & - & - \\
LS & $0,6715^{*}$ & - & - & - \\
CS & $0,6646^{*}$ & $0,3594^{\mathrm{ns}}$ & - & - \\
ES & $0,7134^{*}$ & $0,2373^{\mathrm{ns}}$ & $0,4768^{*}$ & - \\
\hline
\end{tabular}

* Significativo a $5 \%$ de probabilidade.

Esses resultados indicam que sementes mais pesadas podem ser encontradas em sementes com espessura e largura maiores, comprovando que os resultados de estudos biométricos podem orientar na colheita em campo. Felizardo et al. (2015), reforçam esse ponto de vista e consideram que essas informaçóes podem auxiliar não apenas favorecer a seleção de lotes de sementes mais uniformes para a realização de plantios, mas também facilitar o beneficiamento industrial das mesmas.

\section{CONCLUSÃO}

As sementes de puerária apresentaram maior quantidade de sementes dura em tratamentos que não houve o rompimento do tegumento.
O tratamento mais eficiente foi a escarificação com lixa, permitindo maior permeabilidade do tegumento.

As sementes analisadas por meio da característica física (morfométrica) apresentaram baixo coeficiente de variação, caracterizando o lote analisado com tendência de homogeneidade.

\section{LITERATURA CITADA}

ANDRADE, A. C. S.; LOUREIRO, B. M.; SOUZA, A. D. de O.; RAMOS, F. N. Quebra de dormência de sementes de sucupira-preta. Pesquisa Agropecuária Brasileira, Brasília, v. 32, n. 5, p. 465-469, maio 1997.

AYRES, M.; AYRES JUNIOR, M.; AYRES, D.L.; SANTOS, A.A. S. Biostat 5.0: aplicaçóes estatísticas nas áreas das ciências biológicas e médicas. Brasília: Sociedade Civil Mamirauá-Belém (MCT-CNPq), Belém. 364p. CD-ROM. 2007.

BRASIL. Ministério da Agricultura e Reforma Agrária. Regras para análise de sementes. Brasília: SNDA/DNDV/ CLAV, 2009. $365 \mathrm{p}$.

COSTA, N. de L. Pueraria: leguminosa forrageira para a produção de proteína. Porto Velho: Embrapa Rondônia, 1990. 4 p. (Comunicado Técnico, 92).

COSTA, N. de L.; PAULINO, V. T.; LUCENA, M. A. C.; SCHUNKE, R.; LOPES, R. B.; MAGALHÃES, J. A.; NASCIMENTO, L. E. S. Resposta de Pueraria phaseoloides (Benth.) à adubação fosfatada em presença ou não de fungo micorrízico. Pubvet (Londrina), v.6, n.9, Art.1315, 2012.

DIAS-FILHO, M. B. Degradação de pastagens: processos, causas e estratégias de recuperação. Ed. 4. Belém: Edição do Autor, abr. 2011.215p.

DIAS-FILHO, M. B. Diagnóstico das pastagens no Brasil. Belém, PA: Embrapa Amazônia Oriental, 2014. 36 p. (Embrapa Amazônia Oriental. Documentos, 402).

FELIZARDO, S. A.; FREITAS, A. D. D. de; MARQUES, N. S.; BEZERRA, D. A. Características biométricas de frutos e sementes de Oenocarpus bataua Mart. com procedência de Almeirim, Pará. Revista Verde de Agroecologia e Desenvolvimento Sustentável. Pombal, PB. v.10, n 5, p. 09-15, dez. 2015.

GAMA, J. S. N.; ALVES, E. U.; BRUNO, R. de L. A.; PEREIRA JUNIOR, L. R.; BRAGA JUNIOR, J. M.; MONTE, D. M. de O. Superaçáo de dormência em sementes de Centrosema plumieri Benth. Revista Brasileira de Sementes, v. 33, n. 4, p. 643 - 651, 2011.

MACEDO, M. C. DE; SCALON, S. D. P. Q.; SARI, A. P.; Biometria de frutos e sementes e germinação de Magonia pubescens ST.Hil (Sapindaceae). Revista Brasileira de Sementes, v. 31, n. 2, p. 202-211, 2009. 
MAGUIRE, J. D. Speed germination-aid in selection and evaluation for seedling emergence and vigor. Crop Science, Madison, v. 2, n.1, p. 176-177, 1962.

MARQUES, T. E. D.; BAÊTA, H. E.; LEITE, M. G. P.; MARTINS, S. V.; KOZOVITS, A. R. Crescimento de espécies nativas de cerrado e de Vetiveria zizanioides em processos de revegetação de voçorocas. Ciência Florestal, Santa Maria, v. 24, n. 4, p. 843-856, out.-dez., 2014.

MEDEIROS FILHO, S.; FRANÇA E. A.; INNECCO R. Germinação de sementes de Operculina macrocarpa (L.) Farwel E Operculina alata (Ham.) Urban. Revista Brasileira de Sementes, vol. 24, no 2, p.102-107, 2002.

MELO M. da G. G. de; MENDONÇA, M. S. de; NAZÁRIO, P.; MENDES, A. M. da S., Superação de dormência em sementes de três espécies de Parkia spp. Revista Brasileira de Sementes, v. $33, n^{\circ} 3$ p. $533-542,2011$.

MMA. Mapas de Cobertura Vegetal. Ministério do Meio Ambiente. Site Institucional disponível em: <www.mma.gov.br/ estruturas/arquivos/mapas_cobertura_vegetal.pdf $>$. Acesso em: 02/10/2017.

MONTEIRO, E.M.M.; LOURENÇO JÚNIOR, J.B.; SANTOS, N.F.A.; ARAÚJO, C.V.; FATURI, C.; GARCIA, A.R. Pueraria phaseoloides Benth: alternativa na suplementação de ruminantes em períodos de escassez de forragem na Amazônia. Amazônia, Ciência e Desenvolvimento, v. 4, n. 8, p. 217-228, 2009.

OLIVEIRA, P. F. de; FIRMINO, J. L.; ALMEIDA, M. de C.; MITOSO, P.C.; FERREIRA, D. H.; FERREIRA, D.H.; Aspectos $\mathrm{da}$ biometria dos frutos e sementes de Cariniana domestica (Martius) miers nativa do leste do Acre. In: Reunião Anual da SBPC, 64, 2012, São Luís. Resumos...São Luís: Sociedade Brasileira para o Progresso da Ciência, 2012.

PEDRON, F. A., MENEZES, J. P.; MENEZES, N. L. Parâmetros biométricos de fruto, endocarpo e semente de butiazeiro. Ciência Rural, Santa Maria, v. 34, n. 2, p.585-586, 2004.

PINHEIRO, R. M.; MACEDO, V. G. K.; SOARES, V. N.; BARROS, A. C. S. A.; TUNES, L. V. M.; FERREIRA, E. J. L.; LOPES, J. M. Viabilidade das sementes de puerária (Pueraria phaseoloides (Roxb.) Benth.) oriundas do Acre e com diferentes coloraçôes. In: XX Congresso Brasileiro de Sementes, 2017, Foz do Iguaçu. Anais... XX Congresso Brasileiro de Sementes, 2017.

RIVERO, S.; ALMEIDA, O.; ÁVILA, S.; OLIVEIRA, W. Pecuária e desmatamento: uma análise das principais causas diretas do desmatamento na Amazônia. Ambiente Sociedade. v.15 no.2 São Paulo May/Aug. 2012.

SAMPAIO, L. S. de V.; PEIXOTO, C. P.; PEIXOTO, M. de F. da S. P.; COSTA, J. A.; GARRIDO, M. da S.; MENDES, L. N. Ácido sulfúrico na superação da dormência de sementes de sucupira preta (Bowdichia virgilioides Kunth. - Fabaceae). Revista Brasileira de Sementes, Brasília, v. 23, n. 1, p. 184-190, 2001.
SOUZA FILHO, A. P da SILVA; SILVA, M. A; DUTRA, S. Quebra de dormência em sementes de Pueraria phaseoloide (roxburgh) Bentham. Pasturas tropicales, v. 21 n. 2 [S/d]. 